\title{
Managing the Risk of Adverse Events Using the Example of a Hospital in Wroclaw
}

\author{
Agata Lisiewicz Kaleta ${ }^{1}$, Aleksandra Sierocka ${ }^{2}$, Petre Iltchev ${ }^{3}$, \\ Michał Marczak ${ }^{3}$ \\ 1 The 4th Military Clinical Hospital with Policlinic SPZOZ in Wroclaw, Poland \\ 2 K. Jonscher Hospital in Lodz, Poland \\ ${ }^{3}$ Health Care Policy Department, Medical University of Lodz, Poland
}

\begin{abstract}
Health Care Centres are institutions which, because of their specificity and character, are particularly exposed to various kinds of risk. One of the most important and most frequently used methods of risk management is the black spots method. The research material collected for the study comes from one of the hospitals in Wrocław. All hospital stays of the C22 (Face and Jaw Surgery Ward) and H05 (Injury and Orthopaedics Surgery Ward) settlement groups (DRG) were analysed - a total of 178 hospitalisations. The black spots method was used in the study, which consisted of risk identification, the ordering of threats and proposals for remedial actions. Using the black spots method, it was possible to identify adverse events that occurred during the hospitalisation of patients with H05 and C22 DRGs in the Injury and Orthopaedics Surgery Ward and Facial and Jaw Surgery Ward. In both cases, the treatment costs for patients with complications were higher than for the stays without complications.
\end{abstract}

\section{Introduction}

For medical entities that provide medical services, the option of identifying characteristic risk not only brings with it advantages to the patients and the hospital environment, but also ensures correct operation of the health care entities.

Being able to identify and classify adverse events and series of various faults enables the management to realise how many factors and elements may influence their occurrence.

That is why the basic goal of the black spots method (Domejko et al., 2012 ) is to gain as complete knowledge as possible regarding the areas of risk that are present - a knowledge which forms a necessary and required part of 


\section{Agata Lisiewicz Kaleta et al.}

the process, enabling not only the identification of sources of potential risks, but also indicating those that cause the most damage, and are important for the correct operation of the health care facility, including the safety of the patients.

The literature connected with this topic lacks analysis of complications and adverse events during facial surgery. However, research on traumaorthopedic surgery is available. Our research is based on the works of: Arvidsson S. (1996), Friedman R. J. (2013), Ouchterlony J. (1995), and Milgrom P. (1975).

\section{Material and Methods}

The research material collected for the study comes from one of the hospitals in Wrocław. All hospital stays with the C22 (Face and Jaw Surgery Ward) and H05 (Injury and Orthopaedics Surgery Ward) settlement group (DRG) were analysed, a total of 178 hospitalisations.

The black spots method was used in the study, which consisted of risk identification, ordering of threats and proposals of remedial actions, such as e.g. monitoring or tightening of procedures. When constructing models, various factors related to the hospital environment were taken into account, such as the procedures performed (in accordance with ICD-9), hospitalization time, number of days with vascular catheter, number of surgical procedures performed during hospitalisation, number of infections, number of bedsores, duration of surgery and critical events that occurred during hospitalization, resulting in death/disability/longer stay and all other complications.

An attempt was made to identify and assess the black spots. Three basic explanatory variables were adopted for the black spots method: the level of risk in a medical category, average costs, and extraordinary costs (concerning complications). These variables resulted naturally from the research goals (analysis of adverse events) and the possibility of obtaining appropriate data in the analysed hospital (cost analysis, expert risk analyses, proposals of remedial and preventive actions).

Cost data collected in the hospital information system was applied for the calculation of direct medical costs. Direct medical costs include the costs of hospitalization (medical procedures, pharmaceuticals, including extracted costs of antibiotics, material costs, costs of anesthetic procedures, and cost of patients' daily stays in the ward). 
Managing the Risk of Adverse Events Using the Example of a Hospital...

\section{Results}

The analysed data enabled the identification of adverse events that occurred while analysed medical services were being provided, their number, and patients' stay durations associated with the adverse events (Table 1-2). For the C22 group in the Face and Jaw Surgery Ward, the average general hospitalisation time was 4.78 days. The minimum duration of stay was 1 day, the maximum was 33 days, the median was 4 days and the modal value was 3 days.

Table 1. Adverse events identified during the analysis of the C22 group in the Face and Jaw Surgery Ward

\begin{tabular}{|c|c|c|c|c|c|c|}
\hline 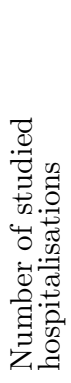 & 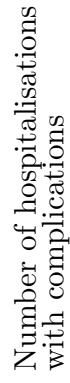 & Incident (adverse event/complication) & 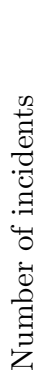 & 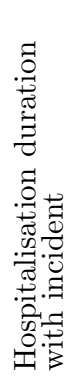 & 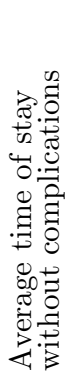 & 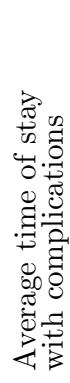 \\
\hline \multirow{9}{*}{95} & \multirow{9}{*}{19} & $\begin{array}{l}\text { Redness at the location of central } \\
\text { intravenous catheter insertion }\end{array}$ & 8 & 5.3 & \multirow{9}{*}{4.1} & \multirow{9}{*}{7.5} \\
\hline & & Increased temperature & 3 & 5.7 & & \\
\hline & & Weakening, ill-being & 1 & 12 & & \\
\hline & & Intravenous cannula occluded & 3 & 5.3 & & \\
\hline & & $\begin{array}{l}\text { Tenderness at the location of central } \\
\text { intravenous catheter insertion }\end{array}$ & 2 & 9 & & \\
\hline & & $\begin{array}{l}1^{\text {st }} \text { degree dermatological changes at the } \\
\text { location of central intravenous catheter } \\
\text { insertion }\end{array}$ & 3 & 5.3 & & \\
\hline & & $\begin{array}{l}\text { Multiple insertions due to the cannula } \\
\text { leaking }\end{array}$ & 1 & 33 & & \\
\hline & & Facial nerve VII paralysis on the left side & 1 & 12 & & \\
\hline & & Repeated surgery & 1 & 3 & & \\
\hline
\end{tabular}

For the H05 group in the Injury and Orthopaedics Surgery Ward, the average general hospitalisation time was 14.35 days. The minimum duration of stay was 10 days, the maximum was 22 days, and the median and modal 
Agata Lisiewicz Kaleta et al.

Table 2. Adverse events identified during the analysis of the H05 group in the Injury and Orthopaedics Surgery Ward

\begin{tabular}{|c|c|c|c|c|c|c|}
\hline 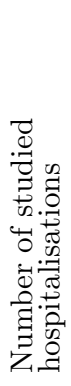 & 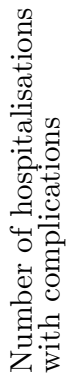 & Incident (adverse event/complication) & 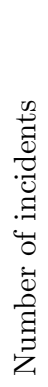 & 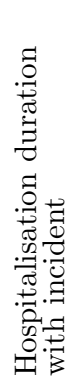 & 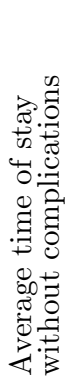 & 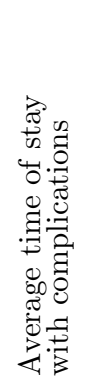 \\
\hline \multirow{8}{*}{83} & \multirow{8}{*}{14} & Intravenous cannula occluded & 1 & 14 & \multirow{8}{*}{14.18} & \multirow{8}{*}{15.14} \\
\hline & & $\begin{array}{l}\text { Redness at the location of central } \\
\text { intravenous catheter insertion }\end{array}$ & 2 & 18 & & \\
\hline & & Post-surgical wound abscess & 1 & 14 & & \\
\hline & & Increased temperature & 8 & 14.75 & & \\
\hline & & Symptoms of pulmonary circulation stasis & 1 & 17 & & \\
\hline & & Inflammation of upper respiratory tract & 1 & 15 & & \\
\hline & & Prolonged urinary incontinence & 1 & 12 & & \\
\hline & & $\begin{array}{l}\text { Urinary tract infection caused by } \\
\text { Enterococcus faecalis }\end{array}$ & 1 & 17 & & \\
\hline
\end{tabular}

values were 14 days. It is also odd that even though all admittances are performed in a planned manner, for each case analysed, the day the procedure was performed on was the $4^{\text {th }}$ or $5^{\text {th }}$ day of the stay. The reason for this may be insufficient patient preparation, e.g. lack of diagnostics or an improper process to control work flow within the hospital ward.

A person per day cost in the examined wards, as well as the costs of examination, used drugs and materials were also calculated. The average cost of stay was calculated on the basis of hospitalisations with and without complications (Table 3). For both studied DRG groups, the costs of hospitalisation during which an adverse event occurred were higher than for hospitalisations without complications.

A detailed analysis of costs of individual complications is presented in Tables 4 and 5 . The difference in costs between hospitalisation with a specific complication and hospitalisation without complications was established based on the indicated data. 
Managing the Risk of Adverse Events Using the Example of a Hospital...

Table 3. Cost data for the C22 and H05 groups (PLN)

\begin{tabular}{|c|c|c|c|c|c|c|c|c|}
\hline Hospitalisation type & 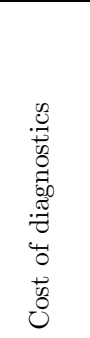 & 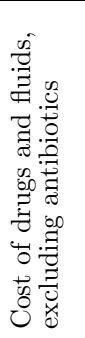 & 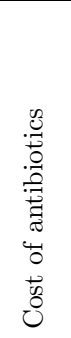 & 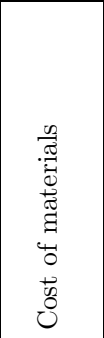 & 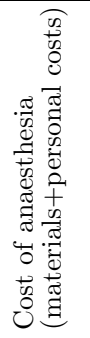 & 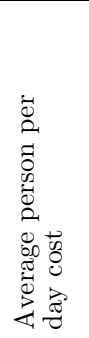 & 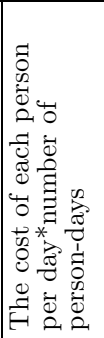 & 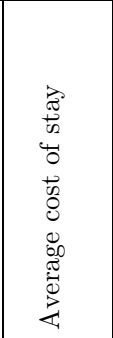 \\
\hline \multicolumn{9}{|c|}{ H05 } \\
\hline without complications & 293.20 & 147.90 & 4.12 & 5435.10 & 344.39 & 391.27 & 5513.19 & 11723.67 \\
\hline with complications & 341.14 & 194.55 & 22.80 & 5508.91 & 328.60 & 375.64 & 5828.55 & 12280.06 \\
\hline difference & 47.94 & 46.66 & 18.68 & 73.81 & -15.79 & -15.64 & 315.36 & 556.39 \\
\hline \multicolumn{9}{|c|}{$\mathrm{C} 22$} \\
\hline without complications & 109.67 & 17.39 & 21.64 & 472.10 & 231.94 & 698.02 & 2796.95 & 3579.79 \\
\hline with complications & 173.65 & 41.32 & 44.88 & 528.01 & 358.38 & 626.20 & 5144.24 & 6262.47 \\
\hline difference & 63.98 & 23.94 & 23.24 & 55.91 & 126.44 & -71.82 & 2347.28 & 2682.68 \\
\hline
\end{tabular}

Table 4. Detailed analysis of H05 hospitalisation costs with complications (PLN)

\begin{tabular}{|c|c|c|c|c|c|c|c|c|}
\hline $\begin{array}{c}\text { Incident } \\
\text { (adverse event/complication) }\end{array}$ & 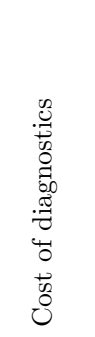 & 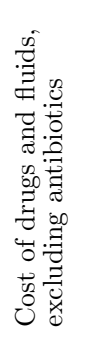 & 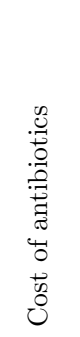 & 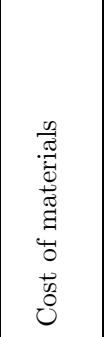 & 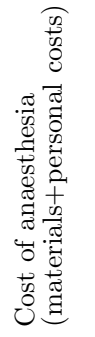 & 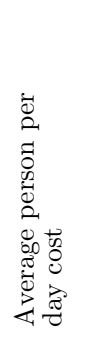 & 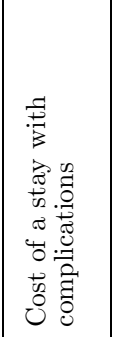 & 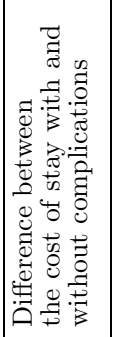 \\
\hline Intravenous cannula occluded & 286.13 & 105.67 & 17.29 & 5496.85 & 244.57 & \multirow{8}{*}{388.57} & 11590.49 & -133.18 \\
\hline $\begin{array}{l}\text { Redness at the location of central } \\
\text { intravenous catheter insertion }\end{array}$ & 298.74 & 200.53 & 24.03 & 5652.36 & 459.02 & & 13628.91 & 1905.24 \\
\hline Post-surgical wound abscess & 293.92 & 111.87 & 2.48 & 6052.07 & 244.57 & & 12184.89 & 461.22 \\
\hline Increased temperature & 302.89 & 215.56 & 32.90 & 5479.14 & 312.72 & & 12074.62 & 350.95 \\
\hline $\begin{array}{l}\text { Symptoms of pulmonary } \\
\text { circulation stasis }\end{array}$ & 366.05 & 102.51 & 2.45 & 5430.43 & 302.26 & & 12809.37 & 1085.70 \\
\hline $\begin{array}{l}\text { Inflammation of upper } \\
\text { respiratory tract }\end{array}$ & 293.27 & 141.16 & 27.67 & 5267.34 & 296.61 & & 11854.60 & 130.93 \\
\hline Prolonged urinary incontinence & 324.98 & 139.63 & 1.37 & 6400.46 & 302.26 & & 10831.54 & -892.13 \\
\hline $\begin{array}{l}\text { Urinary tract infection caused } \\
\text { by Enterococcus faecalis }\end{array}$ & 766.28 & 309.29 & 4.74 & 5157.63 & 337.11 & & 13180.74 & 1457.07 \\
\hline
\end{tabular}


Agata Lisiewicz Kaleta et al.

Table 5. Detailed analysis of C22 hospitalisation costs with complications (PLN)

\begin{tabular}{|c|c|c|c|c|c|c|c|c|}
\hline $\begin{array}{c}\text { Incident } \\
\text { (adverse event/complication) }\end{array}$ & 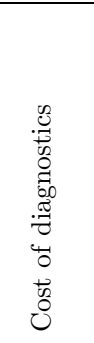 & 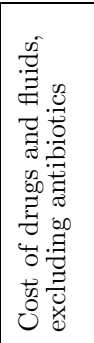 & 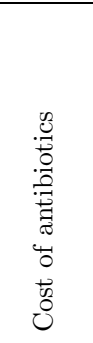 & 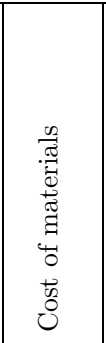 & 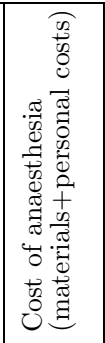 & 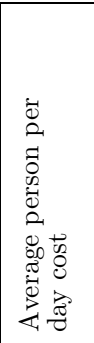 & 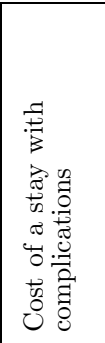 & 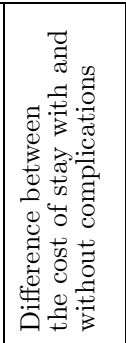 \\
\hline $\begin{array}{l}\text { Redness at the location of central } \\
\text { intravenous catheter insertion }\end{array}$ & 218.59 & 31.52 & 39.36 & 507.92 & 423.24 & \multirow{9}{*}{683.50} & 4824.29 & 1244.50 \\
\hline Increased temperature & 101.94 & 19.96 & 52.65 & 457.62 & 571.24 & & 5042.60 & 1462.81 \\
\hline Weakening, ill-being & 213.62 & 99.84 & 42.54 & 57.85 & $0^{*}$ & & 8615.85 & 5036.06 \\
\hline Intravenous cannula occluded & 143.91 & 63.89 & 63.87 & 683.31 & 562.76 & & 5163.07 & 1583.28 \\
\hline $\begin{array}{l}\text { Tenderness at the location of } \\
\text { central intravenous catheter } \\
\text { insertion }\end{array}$ & 116.12 & 36.56 & 16.93 & 985.85 & 153.27 & & 7460.33 & 3880.54 \\
\hline $\begin{array}{l}1^{\text {st }} \text { degree dermatological changes } \\
\text { at the location of central } \\
\text { intravenous catheter insertion }\end{array}$ & 91.88 & 15.39 & 53.39 & 634.38 & 156.22 & & 4544.53 & 964.74 \\
\hline $\begin{array}{l}\text { Multiple insertions due to the } \\
\text { cannula leaking }\end{array}$ & 271.67 & 193.56 & 124.68 & 780.53 & $0^{*}$ & & 23925.94 & 20346.15 \\
\hline $\begin{array}{l}\text { Facial nerve VII paralysis on the } \\
\text { left side }\end{array}$ & 102.44 & $0^{*}$ & $0^{*}$ & $0^{*}$ & 312.44 & & 8616.88 & 5037.09 \\
\hline Repeated surgery & 40.51 & 23.57 & $0^{*}$ & 3013.07 & 1058.26 & & 3485.91 & -93.88 \\
\hline
\end{tabular}

* no data on the use of drugs/antibiotics/materials

The next step was an expert assessment, enabling the frequency of occurrence of a complication and risk for the patient resulting from that complication to be established (Tables $6-7$ ). The expert team consisted of at least three experts in a given field, who performed the evaluation using a scale of 1 to 5 , where 1 meant very little risk/prevalence, and 5 - very great risk/high prevalence.

With the use of the data presented above, an attempt has been made to identify and assess black spots. The adoption of the three basic predictor variables in the method of black spots, i.e. risk level in medical category, average costs, and extraordinary costs (related to complications), resulted naturally from the research aims (analysis of adverse effects) and from the possibility of obtaining relevant data in the analysed hospital (cost analysis, expert risk analyses, and proportions of corrective and preventive measures). 
Managing the Risk of Adverse Events Using the Example of a Hospital...

Table 6. Expert assessment for complications occurring during H05 settlement group hospitalisations

\begin{tabular}{|l|c|c|}
\hline \multicolumn{1}{|c|}{ Incident (adverse event/ complication) } & $\begin{array}{c}\text { Frequency of } \\
\text { complication on } \\
\text { a scale of 1-5 }\end{array}$ & $\begin{array}{c}\text { Risk for the } \\
\text { patient on } \\
\text { a scale of } 1-5\end{array}$ \\
\hline Intravenous cannula occluded & 2.67 & 1.67 \\
\hline $\begin{array}{l}\text { Redness at the location of central intravenous } \\
\text { catheter insertion }\end{array}$ & 2 & 2 \\
\hline Post-surgical wound abscess & 1.33 & 2.33 \\
\hline Increased temperature & 3.67 & 2.67 \\
\hline Symptoms of pulmonary circulation stasis & 1.33 & 2 \\
\hline Inflammation of upper respiratory tract & 1.33 & 2 \\
\hline Prolonged urinary incontinence & 1.33 & 2 \\
\hline $\begin{array}{l}\text { Urinary tract infection caused by Enterococcus } \\
\text { faecalis }\end{array}$ & 1.33 & 1.67 \\
\hline
\end{tabular}

Table 7. Expert assessment for complications occurring during C22 settlement group hospitalisations

\begin{tabular}{|l|c|c|}
\hline \multicolumn{1}{|c|}{ Incident (adverse event/ complication) } & $\begin{array}{c}\text { Frequency of } \\
\text { complication on } \\
\text { a scale of 1-5 }\end{array}$ & $\begin{array}{c}\text { Risk for the } \\
\text { patient on } \\
\text { a scale of } 1-5\end{array}$ \\
\hline $\begin{array}{l}\text { Redness at the location of central intravenous } \\
\text { catheter insertion }\end{array}$ & 1.33 & 1.33 \\
\hline Increased temperature & 1.67 & 1 \\
\hline Weakening, ill-being & 1.67 & 1 \\
\hline Intravenous cannula occluded & 2 & 1 \\
\hline $\begin{array}{l}\text { Tenderness at the location of central intravenous } \\
\text { catheter insertion }\end{array}$ & 1.67 & 1 \\
\hline $\begin{array}{l}\text { st degree dermatological changes at the location } \\
\text { of central intravenous catheter insertion }\end{array}$ & 1.3 & 1 \\
\hline Multiple insertions due to the cannula leaking & 1.3 & 3 \\
\hline Facial nerve VII paralysis on the left side & 2.67 & 3 \\
\hline Repeated surgery & 3 & \\
\hline
\end{tabular}


Agata Lisiewicz Kaleta et al.

The model was proposed based on research spanning a few years and conducted by a team led by prof. Michał Marczak. The following procedure was adopted (a 3-level procedure), which made it possible to determine critical places that could simultaneously pose considerable risk to patients (Figure 1):

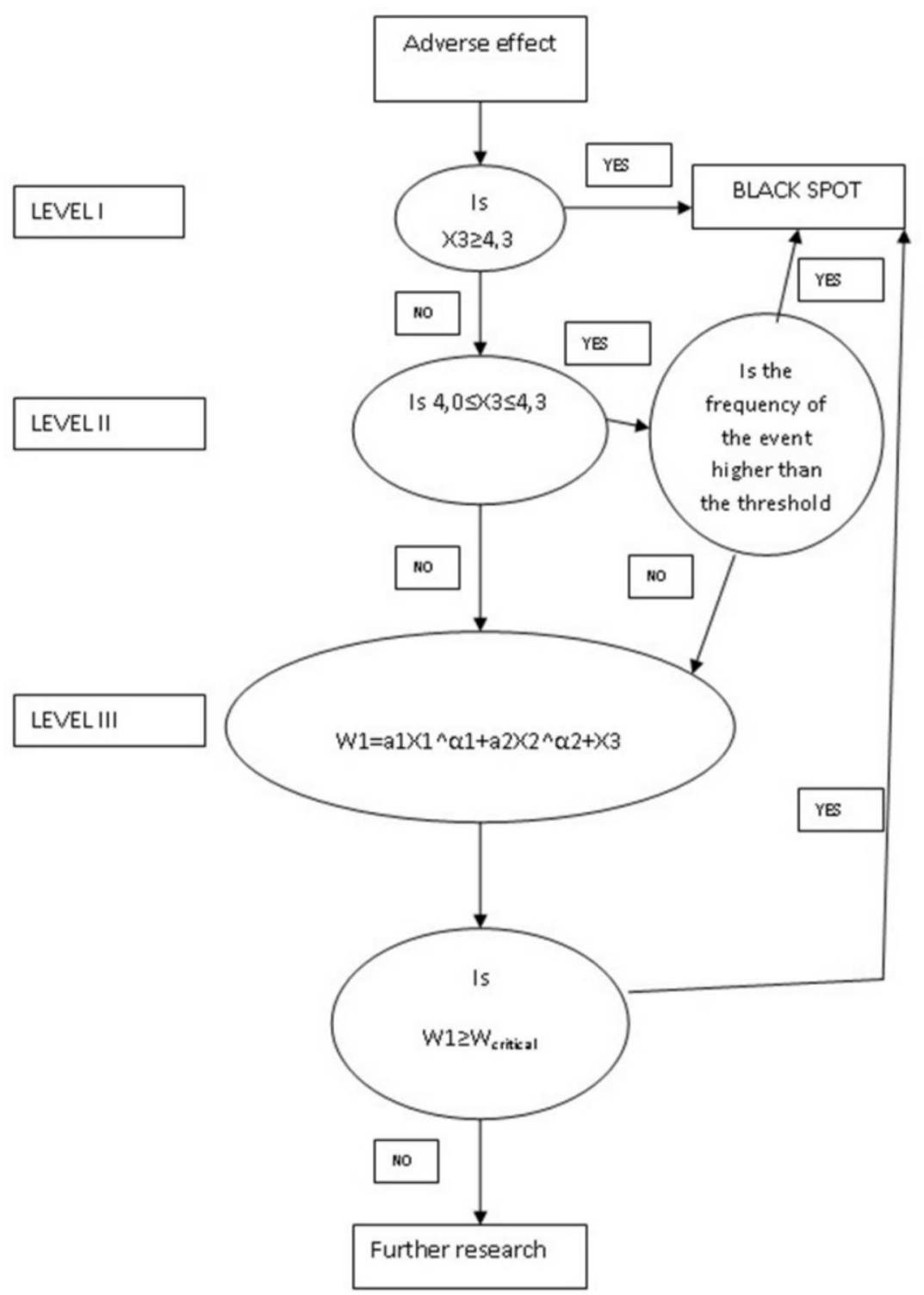

Figure 1. Model of the procedure used for the determination of black spots. Source: (Sierocka et al., 2011) 
Simultaneously, for the needs of the study, the aforementioned formula of $\left(W 1=a 1 X 1^{\wedge} \alpha 1+a 2 X 2^{\wedge} \alpha 2+X 3\right)$ was used on the third level of the model (Figure 1), which takes into consideration many elements, such as:

$X 1$ - ordinary cost

$X 2$ - cost of complication $*$ frequency

X3 - expert assessment

Indexes used in the formula are as follows:

for $\mathrm{H} 05$ :

$$
\begin{aligned}
& a 1=0.0126 \\
& a 2=0.00061 \\
& \alpha 1=0.43973 \\
& \alpha 2=1.44631
\end{aligned}
$$

for $\mathrm{C} 22$ :

$$
\begin{aligned}
& a 1=0.0124 \\
& a 2=0.00056 \\
& \alpha 1=0.43897 \\
& \alpha 2=1.44659
\end{aligned}
$$

Information obtained based on the model and formula presented above made it possible to determine "black spots", simultaneously taking into account three proposed hierarchic levels (Table 8).

Table 8. List of 'black spots' on various hierarchic levels

\begin{tabular}{|c|l|c|c|c|}
\hline \multirow{2}{*}{$\begin{array}{c}\text { Hospitalization } \\
\text { groups }\end{array}$} & \multicolumn{1}{|c|}{ Kind of complication/event } & \multicolumn{3}{|c|}{ Black spot } \\
\cline { 3 - 5 } & Level I & Level II & Level III (W1) \\
\hline \multirow{2}{*}{ C22 } & Increased temperature & NO & NO & YES \\
\hline & $\begin{array}{l}\text { Redness at the location of central } \\
\text { intravenous catheter insertion }\end{array}$ & NO & NO & YES \\
\cline { 2 - 5 } & $\begin{array}{l}\text { Facial nerve VII paralysis on the } \\
\text { left side }\end{array}$ & NO & NO & YES \\
\cline { 2 - 5 } & Repeated surgery & NO & NO & YES \\
\hline
\end{tabular}

\section{Conclusions}

Responding to the issue of risk management in the health care system was dictated by the results of observations concerning phenomena occurring in the health care system that result in the instability of its subjects/elements/components. According to the authors of the project, the most important phenomenon is the lack of effectiveness of adopted risk management programmes (concerning systemic solutions as well as individual subjects of the system). This ineffectiveness has many causes, including the lack of formalized programmes of risk management (e.g. identification, segregation, hierarchization, assessment, neutralization and control), lack of 


\section{Agata Lisiewicz Kaleta et al.}

teams carrying out such programmes, and limiting risk management to neutralizing consequences of those risk components that have already revealed themselves (mainly through insurance protection) instead of undertaking activities to prevent them. Even the most well-constructed and prepared insurance programme (consisting mainly of purchasing insurance, which is a completely passive strategy and also one of the least effective, in terms of economics at least) cannot be a remedy for all identified hazards (Sierocka et al., 2011).

Using the black spots method, it was possible to identify adverse events that have occurred during the hospitalisation of patients with H05 and C22 DRGs in the Injury and Orthopaedics Surgery Ward and Facial and Jaw Surgery Ward. In both cases, the treatment costs for patients with complications were higher than for the stays without complications. Similar tendencies are visible in other studies conducted previously by Professor Marczak's team (Domejko J., 2012; Marczak M, 2008; Sierocka A., 2007; Staszewska A., 2012).

The lack of a detailed list of procedures for which complications occurred makes it difficult to compare our results with other studies. In the future, the results of our research in the field of orthopedic surgery trauma will be compared with those of the American College of Surgeons (ACS) National Surgical Quality Improvement Program (NSQIP) (Molina CS, 2014). When comparing our results with those given by the American College of Surgeons (ACS) National Surgical Quality Improvement Program (NSQIP), excluding cannula obstruction and elevated temperature, our rate of complications was 7 to 83 , determined by all analyzed cases, which gives the percentage of complications of $8.43 \%$. This value is much higher than that given by Molina et al. (2014) - i.e. $5.27 \%$ among the 30 most commonly performed orthopedic procedures, or $3.66 \%$ of all procedures. The percentage of complications in "urinary tract infections", as observed by Molina et al. (2014), is $1.5 \%$ among the 30 most commonly performed orthopedic procedures, or $1.04 \%$ of all procedures. We received a value of $1.2 \%$ for this type of complication. The differences in the observed percentage may have resulted from different methods of performing procedures, a small number of cases analysed and the fact that in our study data was collected from only one hospital. We believe that with greater numbers of analysed cases, more hospitals participating in studies like ours and the growing awareness of this issue among medical personnel, the percentage of reported adverse events/complications will decrease. A study in Sweden of medical records of 395 orthopedic patients reported adverse events in $16 \%$ of patients (Unbeck M, 2008), which differs slightly from our result of 19.27 (16 cases per 
Managing the Risk of Adverse Events Using the Example of a Hospital...

83 patients). Delays in the diagnosis or treatment are also classified as adverse events (Öhrn A, 2012).

\section{R E F E R E N C E S}

Arvidsson, S., Ouchterlony, J., Sjöstedt, L., \& Svördsudd, K. (1996). Predicting postoperative adverse events. Clinical efficiency of four general classification systems. The project perioperative risk. Acta Anaesthesiol Scand, Aug, 40(7), 783-91.

Domejko, J., Sierocka, A., Rybicki, A., Piechota, M., \& Marczak, M. (2012). Identification and analysis of adverse events on the example of SP ZOZ in Swidnica. Studies in Logic, Grammar and Rhetoric. Logical, Statistical and Computer Methods in Medicine, 29(42), 143-157.

Friedman, R. J., Hess, S, Berkowitz, SD, \& Homering, M. (2013). Complication rates after hip or knee arthroplasty in morbidly obese patients. Clin Orthop Relat Res, Oct; 471(10), 3358-66. DOI: 10.1007/s11999-013-3049-9.

Marczak, M., \& Sierocka, A. (2008). The method of black spots and its exemplification for a chosen research hospital. In M. Marczak (Ed.), Risk Management in Health Care System - Methodology and Chosen Examples (pp. 72-83). Łódź, Polska: Wydawnictwo Politechniki Łódzkiej.

Milgrom, P. (1975). Quality control of end results: identifying avoidable adverse events in dentistry. $J$ Am Dent Assoc, 90(6), 1282-90.

Molina, C.S., Thakore, R.V., Blumer, A., Obremskey, W.T., \& Sethi, M.K. (2014). Use of the National Surgical Quality Improvement Program in Orthopaedic Surgery [Abstract]. Clin Orthop Relat Res, April 5. Retrieved from http://www.ncbi.nlm.nih.gov/pubmed/24706043.

Ouchterlony, J., Arvidsson, S., Sjöstedt, L., \& Svärdsudd, K. (1995). Peroperative and immediate postoperative adverse events in patients undergoing elective general and orthopaedic surgery. The Gothenburg study of perioperative risk (PROPER). Part 2. Acta Anaesthesiol Scand, Jul, 39(5), 643-652.

Öhrn, A., Elfström, J., Tropp, H., \& Rutberg, H. (2012). What can we learn from patient claims? - A retrospective analysis of incidence and patterns of adverse events after orthopaedic procedures in Sweden. Patient Saf Surg, January 20, 6(2). DOI: 10.1186/1754-9493-6-2.

Sierocka, A., \& Marczak, M. (2011). Risk management of adverse events in hospitals (case study). Journal of Health Policy, Insurance and Management, May, 8(1), 153-162.

Sierocka, A., Milewska, A., \& Marczak, M. (2007). Zarządzanie ryzykiem w systemie opieki zdrowotnej na przykładzie szpitala w województwie łódzkim. In S. Lachiewicz, \& I. Staniec (Eds.), Sytuacja ekonomiczna, organizacyjna i kadrowa organizacji gospodarczych w aglomeracji tódzkiej (pp. 187-196). Łódź, Polska: Wydawnictwo Media Press. 
Agata Lisiewicz Kaleta et al.

Staszewska, A., Sierocka, A., Rybicki, A., \& Marczak, M. (2012). Identification of adverse events with the use of black spots method - own example. Studies in Logic, Grammar and Rhetoric. Logical, Statistical and Computer Methods in Medicine, 29(42), 171-179.

Unbeck, M., Muren, O., \& Lillkrona, U. (2018). Identification of adverse events at an orthopedics department in Sweden. Acta Orthop 79(3), 396-403. 